\title{
Influence of low grade exercise on skeletal scintigraphy using Tc-99m methylene diphosphonate
}

\author{
Amr Amin'1, Maha Abd El-Kareem¹, Abu Baker Yahia² \\ ${ }^{1}$ Department of Nuclear Medicine, Faculty of Medicine, Cairo University, Cairo, Egypt \\ 2Department of Nuclear Medicine, Maadi Military Hospital, Cairo, Egypt \\ The authors declare that they have no conflict of interest
}

[Received 1 XII 2014; Accepted 20 V 2015]

\begin{abstract}
BACKGROUND: Tc-99m methylene diphosphonate [MDP] bone scan is the basis of the skeletal imaging in nuclear medicine being a highly sensitive tool for detecting bone diseases. Mechanical stimulation induced by low grade exercise or whole-body vibration appears to be advantageous regarding the maintenance and/or improvement of skeletal mass in humans. We aimed to assess the physiological influence of low grade exercise on the quality of skeletal scintigraphy using Tc-99m MDP.

MATERIAL AND METHODS: Tc-99m MDP bone scan was done for 92 volunteers [Group 1; G1]. Five days later, the same subjects were re-scanned [Group 2; G2] after an exercise on treadmill for 5 minutes. Image quality was assessed using quantitative measures whereby equal regions of interest (ROI) were drawn over the femoral diaphysis, and the contralateral adductor area. The total number of counts from the bone [B] ROI and soft tissue [ST] ROI was expressed as a ratio [B:ST ratio] and a mean value for each was established.

RESULTS: Statistically significant difference was found between the B:ST ratio means [p $=0.001$ ] in G1 and G2.

CONCLUSION: This study raised a physiological influence of low grade exercise on the image quality of tc-99m MDP skeletal scintigraphy by increasing MDP osseous uptake.
\end{abstract}

KEY words: bone scan, Tc-99m MDP, physiological effect of exercise, osseous uptake

Nuclear Med Rev 2015; 18, 2: 61-64

\section{Background}

Bone scintigraphy $[\mathrm{BS}]$ is one of the most frequently performed radionuclide procedures. Despite its low specificity, its excellent sensitivity makes it useful in screening and diagnosing some conditions not clearly detected by radiology. Therefore, it remains popular despite advances in magnetic resonance imaging, computed tomography, and positron emission tomography [1]. 50\% of Tc-99m Methylene diphosphonates [Tc-99m MDP] accumulates in bone by $2-6$ hours being adsorbed to the osseous mineral phase with relatively little binding to the organic phase. Radiotracer uptake depends primarily on blood flow and rate of new bone formation [2].

In addition to the event of illness, there are other known factors that could interfere with biokinetics of the radiopharmaceuticals $[3,4]$. This could lead to several undesirable consequences, as a misdiagnosis and/or the repetition of the examinations with

Correspondence to: Dr. Amr Amin

32, Soliman Abaza St. Al-Mohandeseen

Giza, Egypt

Post-address: 11123

Tel: +2 0101648583

Fax: +2 02334445

E-mail: amramin67@gmail.com exposure of the patient and staff to radiation overload [4]. Drug interaction with radiopharmaceuticals, radiation therapy, surgical procedures, chemoperfusion, immunotherapy, blood transfusion and renal dialysis are some medical procedures that could induce alterations in biokinetics of radiopharmaceutical and the quality of the nuclear medicine investigation [5-8].

Exercise induced alterations in uptake of a radiopharmaceutical in a target was well established in myocardial SPECT imaging $[9,10]$, and acute swimming exercise was capable of altering bioavailability of Tc-99m MDP in some organs of rats [11]. To our knowledge, using the information obtained in the PubMed [MEDLINE till 2014], no previous studies have evaluated the effect of exercise on osseous uptake of 99mTc-MDP and quality of images in humans. Also, effect of exercise on bone scan imaging is not described in the guidelines $[12,13]$. We aimed to evaluate the influence of low grade exercise on the image quality of BS using Tc-99m MDP.

\section{Material and methods}

The study was approved by the local ethics committee of Cairo University scientific review board and informed consent was obtained from all volunteers according to the Declaration of Helsinki; General Assembly, October 2008 [January 2013]. This prospective 
study included 92 volunteers [ 40 males and 52 females] who were subjected for BS over the period between April 2013 and December 2013. In the selection criteria we excluded those with chronic renal disease, overweight, ages $<15$ and $>50$ years, those unable to exercise or with soft tissue abnormalities especially in the thigh regions as lymphedema.

The patients were imaged 2-3 hours after I.V. injection of Tc-99m MDP [555-740 mBq] [Group 1; G1]. The same subjects were re-scanned [Group 2; G2] similarly but after exercising them for 5 minutes on treadmill at 10 minutes after tracer injection. Timed imaging [169 \pm 28 minutes in G1 and $164 \pm 26$ minutes in G2] was done using Symbia-E dual head gamma camera [Siemens; Germany] mounted with a low energy high resolution collimator [scan speed, $20 \mathrm{~cm} / \mathrm{min}$; ventral contour; matrix, $512 \times 2,048$ ). The whole body field was used to digitally record anterior and posterior views $(256 \times 1024)$ on a dedicated computer system (Syngo-MI VA60B, WinNT5.1 service pack3, Berlin, Germany). Energy discrimination was provided by a 15-20\% window centered on the $140 \mathrm{keV}$ of Tc-99m.

For assessment of image quality we adopted a quantitative parameter [Bone-to-Soft Tissue Ratio (B:ST) calculation]. For B:ST calculation, the counts over an area of the right femoral diaphysis were obtained according to the region-of-interest [ROI] technique. A minimum ROI size of 150 pixels was compared with a similar sized $\mathrm{ROI}$ of the contralateral adductor area. The contralateral medial thigh was used to avoid an overlap with bony structures on the used bony side and taking into consideration absence of significant difference in thigh circumference of each lower extremity. The total number of counts from bone $[\mathrm{B}] \mathrm{ROI}$ and soft tissue [ST] ROI was expressed as a ratio [B:ST ratio] by the calculated means of anterior and posterior views [14]

\section{Statistical analysis}

Data was analyzed using IBM SPSS advanced statistics version-20 [SPSS Inc., Chicago, IL]. Numerical data were expressed as mean and standard deviation [SD] or median and range as appropriate. For quantitative data, comparison between two groups was done using Student $t$-test. Paired $t$-test was used to compare two consecutive measures of numerical variables. $P$-value $<0.05$ was considered significant.

\section{Results}

\section{Study population}

This prospective study included 92 volunteers [ 40 males (43.5\%) and 52 females (56.6)] with a mean age $42.7 \pm 4.4$ year [range 29-49 years]. The patients' physical characteristics and exercise duration are shown in Table 1.

\section{Comparison between both groups}

No significant statistical difference was found between the means of timed imaging [169 \pm 28 minutes and $164 \pm 26$ minutes in $\mathrm{G} 1$ and $\mathrm{G} 2$ respectively; $\mathrm{p}=0.6$.

$\mathrm{B}: \mathrm{ST}$ ratio was performed in both groups and their statistical values are shown in Table 2 being $1.4 \pm 0.2$ and $1.8 \pm 0.3$ in $\mathrm{G} 1$ and $\mathrm{G} 2$ respectively.

There was statistically significant difference between the means of $B: S T$ ratio $[p<0.001$ in $\mathrm{G} 1$ and $\mathrm{G} 2$ (Table 2).

\section{Discussion}

This prospective study was carried out on 92 volunteers to evaluate the effect of low grade exercise on image quality of skeletal scintigraphy using Tc-99m MDP. It showed that low grade exercise could induce increase in Tc-99m MDP osseous uptake providing a higher image quality. As far as we know no previous prospective studies have assessed such aspect in humans.

Tc-99m MDP is used in clinical situations to identify osseous changes based on the strong affinity of hydroxyapatite crystals in mineral phase of the bone to the diphosphonate compounds. Also, Tc-99m MDP allow quantitative measurements in bone that could reflect blood flow and osteoblastic activity $[10,15,16]$.

There is a raised question about effect of exercise on the quality of BS. It was shown that whole body vibration-induced exercises could improve bone mineral density in postmenopausal women [17]. Also, exercises in oscillating platforms inducing whole body vibration (WBV) can improve strength of leg muscle, bone mineral density, and body balancing ability [18-21]. Moreover repeated muscle contractions might exert endocrine and/or metabolic effects with subsequent increase in MDP uptake [22, 23].

Souza et al. [11] evaluated the effects of exercise on the biodistribution of Tc-99m MDP in rates. Exercised group (EG) was adapted

Table 1. Physical characteristics and exercise duration of the study population

\begin{tabular}{|c|c|c|c|c|c|}
\hline Characteristic & Mean & Standard deviation $[ \pm]$ & Median & Minimum & Maximum \\
\hline Height $[\mathrm{cm}]$ & 172.1 & 5.3 & 172 & 161 & 181 \\
\hline Weight [kg] & 75.8 & 3.6 & 67 & 55 & 79 \\
\hline Body mass index (BMI) & 22.5 & 1.5 & 22.4 & 19.3 & 25.9 \\
\hline Duration of exercise [minutes] & 5.1 & 0.4 & 5 & 5 & 6 \\
\hline
\end{tabular}

Table 2. Statistical measures of the non-exercising and exercising Bone:Soft Tissue (B:ST) ratio

$\begin{array}{lccccc} & \text { Mean } & \text { Standard deviation } & \text { Median } & \text { Minimum } & \\ \text { G1; B:ST ratio } & 1.4^{*} & 0.2 & 1.5 & 1 \\ \text { G2; B:ST ratio } & 1.8^{*} & 0.3 & 1.8 & 1.2\end{array}$

G1 - non-exercising group, G2 - exercising group; * $p<0.001$ 
to water for 2 weeks then submitted to exercise [acute swimming] after injection of Tc-99m MDP. After 3 hours rates were sacrificed then blood and organs were analyzed and radioactivity was calculated as percentage/gram of tissue of injected dose $(\% / D / g)$. They showed a significant decrease of \%ID/g in the hearts and lungs of EG compared to the control group with subsequent increase in osseous uptake of Tc-99m MDP. They concluded that exercise could induce specific metabolic modifications in certain organs, which are relevant to osseous uptake of Tc-99m MDP.

On the contrary, Pereira et al. [23] showed significant decrease $(p<0.05)$ in osseous uptake of the Tc-99m MDP in the bones but no significant alterations in its uptake in soft tissues and muscles following vibration induced exercise in rats compared to unexercised rates. We believe this was attributed to the very small sample size [4 exercised and 5 controls] and the early scarifying of rates [ $5 \mathrm{mi}-$ nutes after exercise] that led to insufficient time to show the effect of exercise on osseous uptake of Tc-99m MDP.

Judex et al. [24] reported that after $10 \mathrm{~min}$ of vibration-induced exercise in 3-month-old mice bone volume to total volume (BV/TV) was increased $[\leq 85 \%]$ in the vibrated animal models compared to controls. Moreover, Rubin et al. [25] stated that using low-magnitude vibration or low grade exercises seem to counteract bone loss from the spine and perhaps from hips in post-menopausal women.

Other reports [26-28] suggested that low grade exercises or vibrations may augment skeletal mass through direct or central modulation of tissue perfusion. Besides, understanding of the physiological responses of the endocrine system to acute and chronic exercise-vibratory protocols may be interesting to understand the mechanisms involved in enhanced bone remodeling and its effect on increasing localization of bone imaging radiopharmaceuticals as Tc-99m MDP or [ $\left.{ }^{18} \mathrm{~F}\right]$-sodium fluoride [23].

Alterations in local blood flow and metabolism of organs could lead to modifications of radiopharmaceuticals' uptake [4, 29-31]. Other possible explanations may be that exercise results in an increase in resting metabolic rate and cardiac output [32]. Increase blood flow and vascular permeability after exercise, which in turn increase extraction efficiency, are felt to be also responsible for prompt and further Tc-99m MDP accumulation [32]. Besides; it is known that the kidney is the excretory route of MDP and peak of renal activity is reached after approximately 20 minutes. Within 1 hour and 6 hours [with normal renal function] $>30 \%$ and $>60 \%$ of the unbound complex will undergone glomerular filtration respectively [33]. So, increased renal blood flow following low grade exercise might result in increased excretion of the radiotracer from soft tissues and higher bone to soft tissue ratios [34, 35] as the case in our study.

Finally, though our results were compared with animal studies, but raises low grade exercise after MDP administration as potentially useful technical process which leads to better image quality.

\section{Conclusion}

This study suggested low grade exercise after administration could induce increased osseous uptake of Tc-99m MDP providing a better image quality as proved by quantitative evaluation [B:ST ratios] in normal volunteers.

\section{References}

1. Genant HK, Bautovich GJ, Singh M, Lathrop KA, Harper PV. Bone-seeking radionuclides: an in vivo study of factors affecting skeletal uptake. Radiology 1974; 113: 373-382.

2. Brenner Al, Koshy J, Morey J, Lin C, DiPoce J. The bone scan. Semin Nucl Med 2012; 42: 11-26.

3. Hesslewood S, Leung E. Drug interactions with radiopharmaceuticals. Eur J Nucl Med 1994; 21: 348-356.

4. Bernardo-Filho M, Santos-Filho SD, Moura EG et al. Drug interaction with radiopharmaceuticals: a review. Braz Arch Biol Technol 2005; 48 (special issue): 13-28.

5. Owunwanne A, Patel M, Sadek S. The handbook of radiopharmaceuticals. 1st ed. Chapman \& Hall Medical Co., London 1995.

6. Sampson CB. Textbook of radiopharmacy theory and practice. Gordon and Breach, Amsterdam 1999.

7. Passos M, Ramos C, Dutra SCP, Bernardo-Filho M, Moura EG. Biodistribution of $99 \mathrm{mTc}-\mathrm{O} 4 \mathrm{Na}$ changes in adult rats whose mothers were malnourished during lactation. J Nucl Med 2002; 43: 89-91.

8. Kumakura Y, Danielsen EH, Reilhac A, Gjedde A, Cumming P. Levodopa effect on [18F] fluorodopa influx to brain: Normal volunteers and patients with Parkinson 's disease. Acta Neurol Scand 2004; 110: 188-195.

9. Yang MF, Dou KF, Liu XJ, Yang YJ, He Z. Prognostic value of normal exercise Tc-99m SestaMIBI myocardial tomography in patients with angiographic coronary artery disease. Nucl Med Commun 2006; 27: 333-338.

10. Saha GB. Fundamentals in nuclear pharmacy. Springer-Verlag, New York 2010.

11. Souza DE, Vaisberg M, Brito LC et al. Does acute swimming exercise alter the bioavailability of the radiopharmaceutical technetium-99m methylene diphosphonate (Tc99m -MDP) in Wistar rats? Animal Biology 2011; 61: 403-412.

12. BNMS clinical guidelines. $99 \mathrm{mTc}$ diphosphonate bone imaging for metastases. British Nuclear Medicine Society, 2001. Available on: http:// www.bnms.org.uk/ bnms/images/stories/downloads/documents/microsoft_word___99mtc_diphosphonate_bone_imaging_for_metastases_pdf

13. Donohoe $\mathrm{KJ}$, Brown ML, Collier BD et al. Procedure guideline for bone scintigraphy. Soc Nucl Med Version 3.0 2003; 205-209.

14. Amr A, Mahasan A, Ayah N. Does fluid restriction affect the image quality of skeletal scintigraphy? Iran J Nucl Med 2013; 21: 77-80.

15. McCracken M, Zinn K, Lemons JE et al. Radioimaging of implants in rats using Tc-99m-MDP. Clin Oral Implants Res 2001; 12: 372-378.

16. Blake GM, Park-Holohan SJ, Cook GJR, Fogelman I. Quantitative studies of bone with the use of $18 \mathrm{~F}$-fluoride and $99 \mathrm{mTc}$-methylene diphosphonate. Semin Nucl Med 2001; 31: 28-49.

17. Slatkovska L, Alibhai SM, Beyene J, Cheung AM. Effect of whole body vibration on BMD: a systematic review and metaanalysis. Osteoporosis Int J 2010; 21: 1969-1980.

18. Roelants M, Delecluse C, Goris M, Verschueren S. Effects of 24 weeks of whole body vibration training on body composition and muscle strength in untrained females. Int J Sports Med 2004; 25: 1-5.

19. Dolny DG, Reyes GF. Whole body vibration exercise: training and benefits. Curr Sports Med Reports 2008; 7: 152-157.

20. Von Stengel S, Kemmler W, Engelke K, Kalender WA. Effects of whole body vibration on bone mineral density and falls: Results of the randomized controlled ELVIS study with postmenopausal women. Osteoporosis Int 2010; 22: 317-325

21. Cheung W, Mok $H$, Qin $L$ et al. High frequency whole body vibration improves balancing ability in elderly women. Arch Phys Med Rehabil 2007; 88: 852-857.

22. Di Loreto $\mathrm{C}$, Ranchelli A, Lucidi $\mathrm{P}$ et al. Effects of whole-body vibration exercise on the endocrine system of healthy men. J. Endocrinol Invest $2004 ; 27: 323-327$ 
23. Pereira Mde O, Pinto Nde S, Monteiro Mde O et al. Influence of whole-body vibration on biodistribution of the radiopharmaceutical [99mTc] methylene diphosphonate in Wistar rats. Int J Radiat Biol 2013; 89: 668-672.

24. Judex S, Donahue LR, Rubin C. Genetic predisposition to low bone mass is paralleled by an enhanced sensitivity to signals anabolic to the skeleton. FASEB J 2002; 16: 1280-1282.

25. Rubin C, Recker R, Cullen D et al. Prevention of postmenopausal bone loss by a low-magnitude, high frequency mechanical stimuli: a clinical trial assessing compliance, efficacy and safety. J Bone Miner Res 2004; 19: $343-351$

26. Cardinale $\mathrm{M}$, Wakeling J. Whole body vibration exercises: are vibrations good for you? Br J Sports Med 2005; 39: 585-589.

27. Prisby RD, Lafage-Proust M, Malaval L, Belli A, Vico L. Effects of whole body vibration on the skeleton and other organ systems in man and animal models: what we know and what we need to know. Ageing Res Rev 2008; 7: 319-329.

28. Rittweger J. Vibration as an exercise modality: how it may work and what its potential might be. Eur J Appl Physiol 2010; 108: 877-904.
29. Carlsson S. A glance at the history of nuclear medicine. Acta Oncol 1995; 34: 1095-1102.

30. Chandra R. Nuclear Medicine Physics the basics. 5th ed. Williams and Wilkins, New York 1998.

31. Khalil MM, Tremoleda JL, Bayomy TB, Gsell W. Molecular SPECT Imaging: an overview. Int J Mol Imaging 2011; 2011: 796025

32. Higginbotham MB, Morris KG, Williams RS et al. Regulation of stroke volume during submaximal and maximal upright exercise in normal man. Circ Res 1986; 58: 281-291

33. Bombardieri E, Aktolun C, Baum RP et al. Bone scintigraphy: procedure guidelines for tumour imaging. Eur J Nucl Med Mol Imaging 2003; 30: BP99-BP106.

34. Totosy de Zepetnek JO, Giangregorio LM, Craven BC. Whole body vibration as potential intervention for people with low bone mineral density and osteoporosis: a review. J Rehabil Res Dev 2009; 46: 529-542.

35. Pinto NS, Monteiro MB, Santos-Filho SD et al. Postmenopausal/menopause, bone mineral density and whole body vibration: a short review. J Med Med Sci 2010; 11: 516-525. 